\title{
Reassessment of shortwave surface cloud radiative forcing in the Arctic: consideration of surface-albedo-cloud interactions
}

Johannes Stapf et al.

Correspondence to: Johannes Stapf (johannes.stapf@uni-leipzig.de)

The copyright of individual parts of the supplement might differ from the CC BY 4.0 License. 


\section{Impact of flight altitude on the surface radiative energy budget and cloud radiative forcing derived from low-level flights during the ACLOUD campaign}

During ACLOUD $16 \mathrm{~h}$ of low-level flights were carried out to characterize the surface radiative energy budget, among other aspects (Wendisch et al., 2019). A visual impression of these low-level flight sections is given in Fig. S1.

The atmosphere between the aircraft and the surface (in average $80 \mathrm{~m}$ during the ACLOUD campaign) will influence the obtained irradiances if compared to real ground-based observation (surface radiative energy budget).

In order to investigate the potential errors caused by this specific measurement approach, radiative

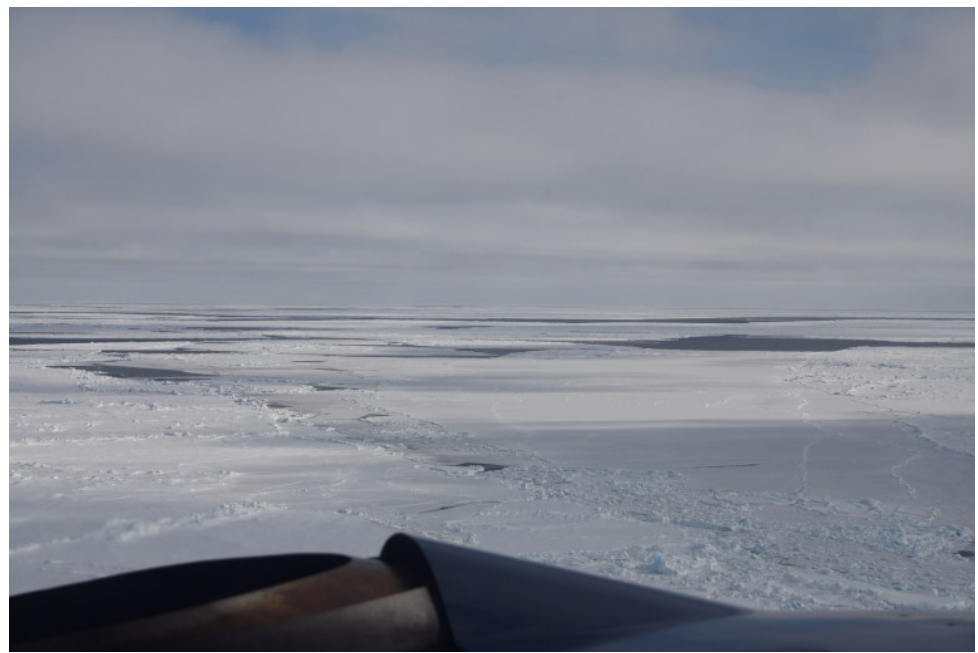

Figure S1 Typical flight situation captured through the aircraft window during a low-level section of the ACLOUD campaign. Flight altitude is approximately $65 \mathrm{~m}$, the cloud base height approximately $250 \mathrm{~m}$. transfer simulations have been performed.

The simulations are implemented with the same settings as described in the study and performed for all atmospheric profiles obtain during the ACLOUD/PASCAL campaign including: radiosoundings from NyÅlesund (Svalbard) and the research vessel Polarstern (concurrent PASCAL campaign), dropsondes released from the Polar 5 research aircraft, as well as in situ profiles obtained during descents/ascents before/after low-level sections by the two aircraft Polar 5 and Polar 6 ; in total 402 profiles. The datasets are referenced in the section "Data availability" in the paper and should represent the regional characteristics of atmospheric profiles during the ACLOUD/PASCAL campaign. For the shortwave simulations a surface albedo of 0.8 and a solar zenith angle (SZA) of $60^{\circ}$ was assumed; representative for the ACLOUD conditions.

\section{Estimate of surface radiative energy budget}

\subsection{Longwave Irradiances}

In Fig. S2 the simulated longwave irradiances are shown as a vertical profile for each of the obtained atmospheric profiles. The net longwave irradiance (Fig. S2a) observed in the average flight altitude (blue dashed horizontal line) are in average $1.35 \mathrm{Wm}-2$ more negative (outgoing) compared to theoretical surface-based observations. Looking at the single components, the downward (Fig. S2b) and upward irradiance (Fig. S2C) is underestimated due to the in average warmer near surface air temperatures relative to the air temperature in flight altitude, characteristic for the common summertime atmospheric boundary layer (mostly neutral) observed during ACLOUD. During cold air outbreaks over water a strong negative lapse rate in the levels below the aircraft is found, explaining the outliers of stronger underestimate, while rarely observed surface based inversions cause a slight overestimate of upward and downward irradiances. 

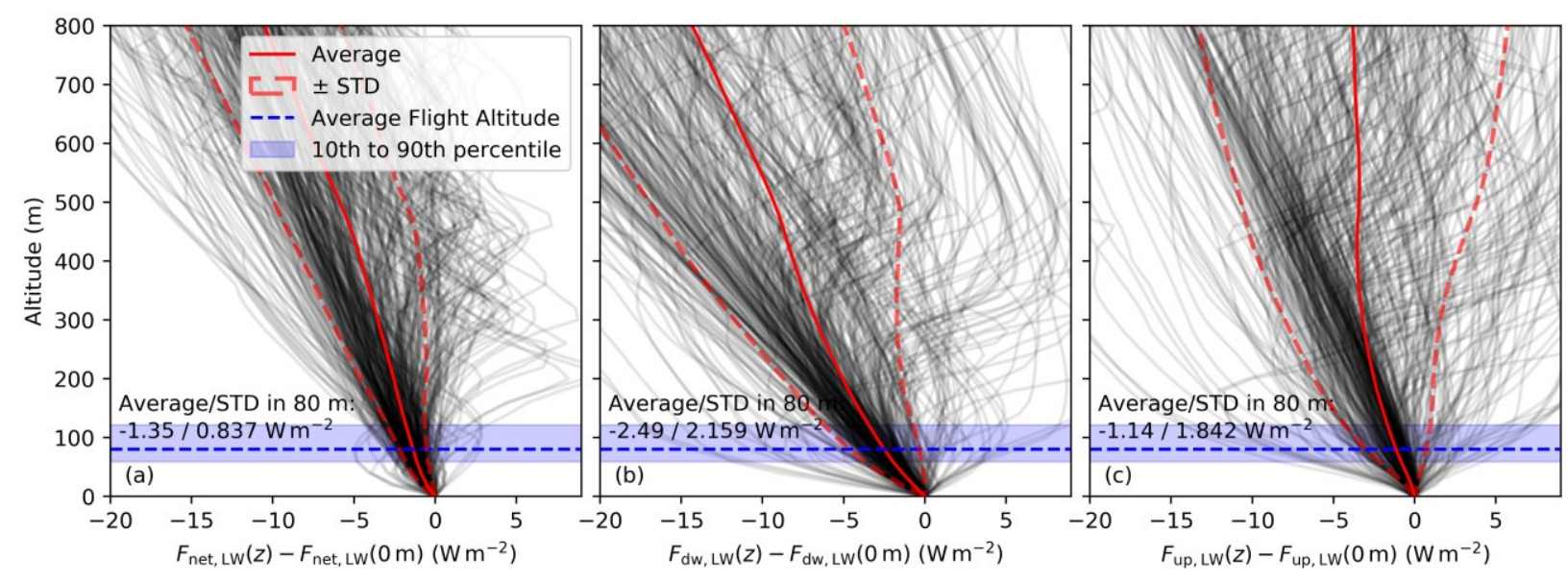

Figure S2 Simulated vertical profiles of the difference between longwave net (a), downward (b), and (c) upward irradiance in flight altitude and irradiances at the surface for all atmospheric profiles obtained during ACLOUD/PASCAL. STD is standard deviation. Blue shadings represent the $10^{\text {th }}$ and $90^{\text {th }}$ percentile of low-level flight altitude during ACLOUD.

\subsection{Shortwave Irradiances}

Relevant for the shortwave radiative transfer is the absorption and scattering between the surface and the aircraft. In Fig. S3a it is shown that in average the net shortwave irradiances is overestimated by the airborne observations by $1.8 \mathrm{Wm}$-2. The downward irradiance (Fig. S3b) is overestimated slightly, while the upward irradiance (Fig. S3C) is underestimate by neglecting the extinction between aircraft and surface.
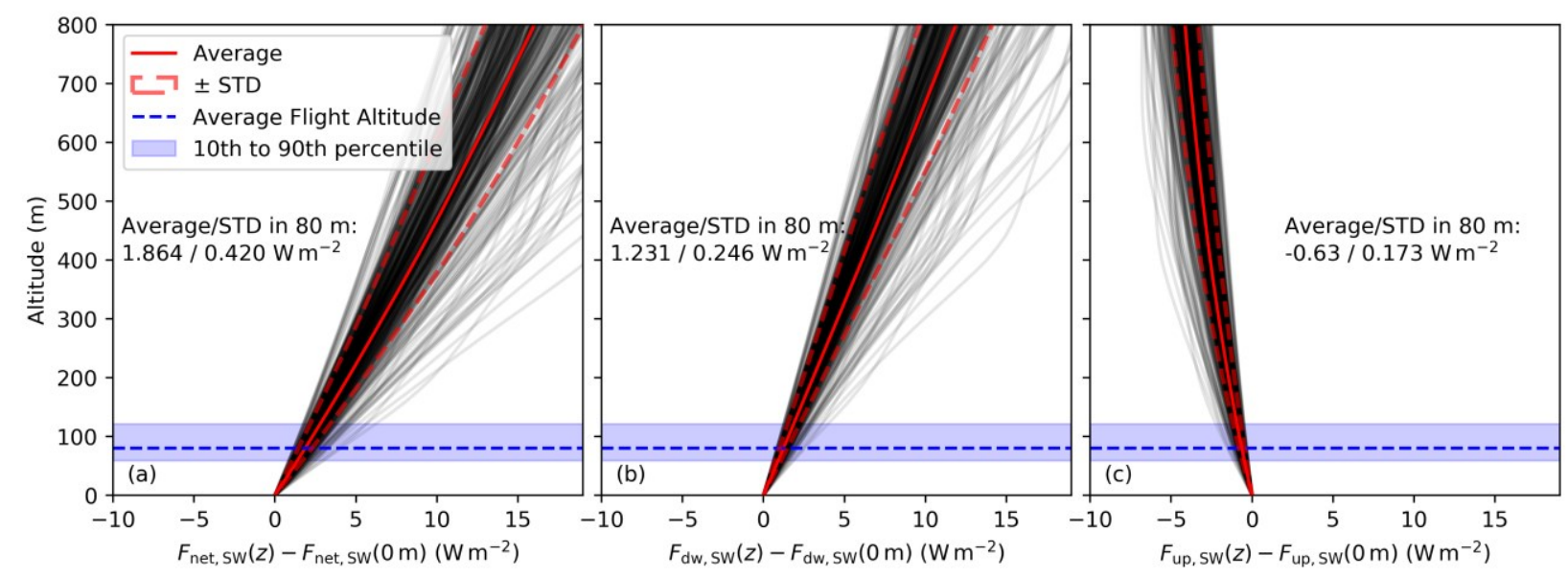

Figure S3 Simulated vertical profiles of the difference between shortwave net (a), downward (b), and (c) upward irradiance in flight altitude and irradiances at the surface for all atmospheric profiles obtained during ACLOUD/PASCAL. STD is standard deviation. Blue shadings represent the $10^{\text {th }}$ and $90^{\text {th }}$ percentile of low-level flight altitude during ACLOUD.

\section{Estimate of cloud radiative forcing (CRF)}

In order to analyze the impact of flight altitude on the estimate of CRF during ACLOUD in the radiative transfer simulations, a cloud extending from 200 to $400 \mathrm{~m}$ with a height-constant liquid water content (LWC) of $0.25 \mathrm{gm}-3$ (liquid water path (LWP) of $50 \mathrm{gm}-2$ ) is included, regardless the prevailing conditions (like surface-based inversions). SZA and surface albedo is set to $60^{\circ}$ and 0.8 , respectively. Results are shown 
in Fig. S4, using again the surface as a reference. An important aspect is that due to the fact that the vertical gradient of downward and upward irradiances below clouds remains almost the same with or without a cloud in the radiative transfer simulations (for atmospheric profiles as observed during ACLOUD), this compensating effect reduces the expected bias in CRF.

\subsection{Shortwave CRF}

The shortwave CRF (cooling effect) in flight altitude (Fig. S4a) is slightly overestimated by below $1 \mathrm{Wm}-2$. Average shortwave CRF values result in $-36.97 \mathrm{Wm}-2$ observed in the average flight altitude instead of $36.02 \mathrm{Wm}-2$ at the surface (deviation of $2.5 \%$ ).

\subsection{Longwave CRF}

In Fig. S4b the uncertainties in the longwave CRF induced by the flight altitude relative to the surface are shown. In average, the average flight altitude causes an overestimate of the derived longwave CRF (warming effect) of $1.1 \mathrm{Wm}-2$. Average longwave CRF values result in $81.71 \mathrm{Wm}-2$ observed in the average flight altitude instead of $80.57 \mathrm{Wm}-2$ at the surface (deviation of $1.4 \%$ ).

The longwave and shortwave CRF overestimates almost compensate for the total CRF, as it is shown in Fig. S4c.
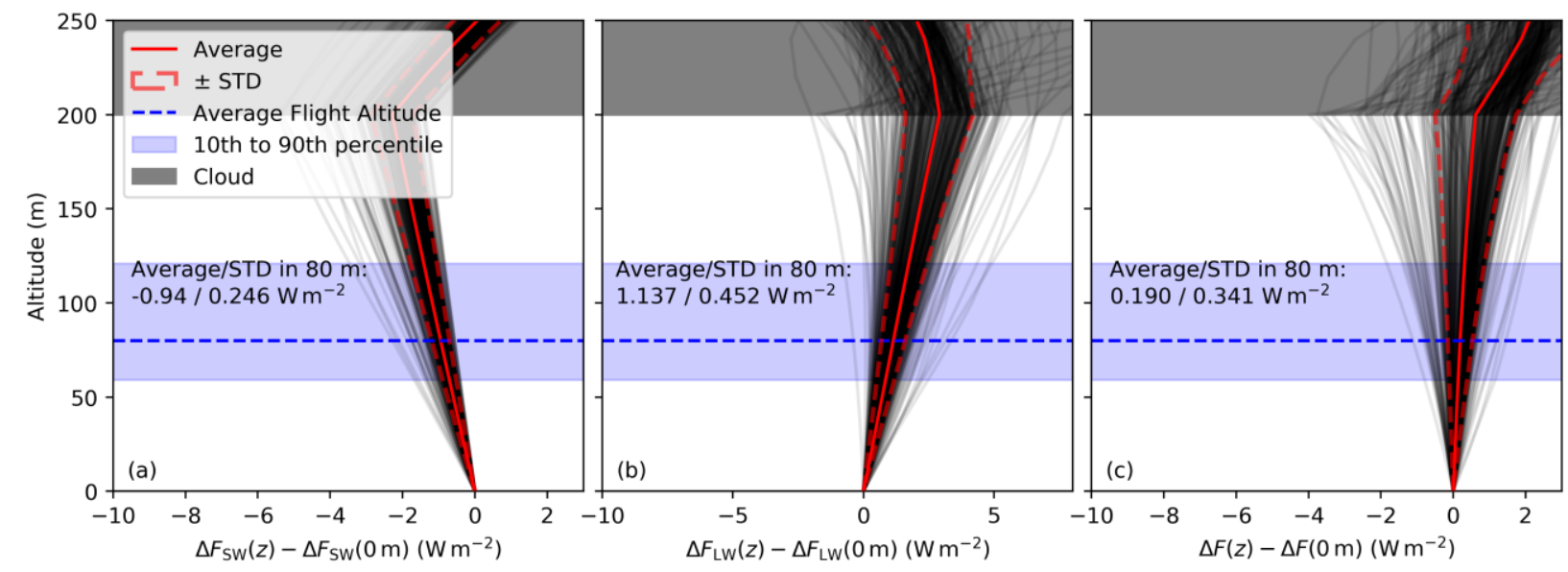

Figure S4 Simulated vertical profiles of the difference between shortwave (a), longwave (b), and total CRF (c) derived in flight altitude and the surface. STD is standard deviation. Blue shadings represent the $10^{\text {th }}$ and $90^{\text {th }}$ percentile of low-level flight altitude during ACLOUD.

\section{References:}

Wendisch, M., Macke, A., Ehrlich, A., Lüpkes, C., Mech, M., Chechin, D., Barrientos, C., Bozem, H., Brückner, M., Clemen, H.-C., Crewell, S., Donth, T., Dupuy, R., Ebell, K., Egerer, U., Engelmann, R., Engler, C., Eppers, O., Gehrmann, M., Gong, X., Gottschalk, M., Gourbeyre, C., Griesche, H., Hartmann, J., Hartmann, M., Herber, A., Herrmann, H., Heygster, G., Hoor, P., Jafariserajehlou, S., Jäkel, E., Järvinen, E., Jourdan, O., Kästner, U., Kecorius, S., Knudsen, E. M., Köllner, F., Kretzschmar, J., Lelli, L., Leroy, D., Maturilli, M., Mei, L., Mertes, S., Mioche, G., Neuber, R., Nicolaus, M., Nomokonova, T., Notholt, J., Palm, M., van Pinxteren, M., Quaas, J., Richter, P., Ruiz-Donoso, E., Schäfer, M., Schmieder, K., Schnaiter, M., Schneider, J., Schwarzenböck, A., Seifert, P., Shupe, M. D., Siebert, H., Spreen, G., Stapf, J., Stratmann, F., Vogl, T., Welti, A., Wex, H., Wiedensohler, A., Zanatta, M., and Zeppenfeld, S.: The Arctic cloud puzzle: using ACLOUD/PASCAL multi-platform observations to unravel the role of clouds and aerosol particles in Arctic amplification, B. Am. Meteorol. Soc., 100 (5), 841-871, https://doi.org/10.1175/BAMS-D-18-0072.1, 2019. 